\title{
PROCESS OF WETLAND LOSS IN THE LOWER NAKDONG RIVER, SOUTH KOREA
}

\author{
IM, R. Y. ${ }^{1,2}-$ KIM, J. Y. ${ }^{2}-$ JOO, G. J. ${ }^{2}-$ DO, Y. ${ }^{2 *}$

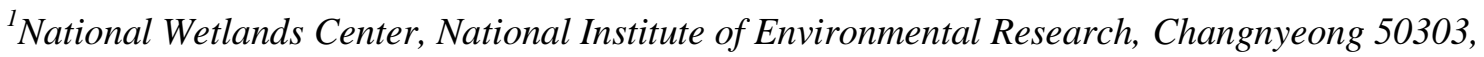 \\ Republic of Korea \\ ${ }^{2}$ Department of Biological Sciences, Pusan National University, Busan 46241, \\ Republic of Korea \\ (phone: +82-51-510-3344; fax: +82-51-583-0172) \\ ${ }^{*}$ Corresponding author \\ e-mail:doyunho@gmail.com \\ (Received 21 $1^{\text {st }}$ Nov 2015; accepted 26 $6^{\text {th }}$ Sep 2016)
}

\begin{abstract}
The historical distribution of wetlands, the process of wetland loss, and the factors responsible for it in South Korea during the past century were investigated to identify trends in wetland loss. Numerous wetlands were lost because of human activities associated with economic development, such as agricultural development, industrialization, and urbanization. The process of wetland loss and alternation were categorized into five types. (1) Wetlands were directly lost by reclamation and development of agricultural land. (2) Levees were constructed on wetlands to prevent flood damage to agricultural land. (3) Houses for farmers were built on the wetlands after reclamation. (4) Roads constructed as infrastructure for farms fragmented the wetlands into small parts. (5) Factories were built on wetlands and paddy fields.
\end{abstract}

Keywords: conservation; historical change; restoration; wetland loss

\section{Introduction}

Wetlands are a complex habitat with both aquatic and terrestrial characteristics. Many species are well adapted to live in these habitats (Keddy, 2010). Humans have also relied upon wetlands as a long-term source of natural resources. Wetland components such as water, land, and wildlife have made huge contributions to human livelihoods (Assessment, 2005). Various wetland components should coordinate harmoniously with each other to retain the services of the wetland ecosystem. However, an attitude prevails wherein only a one-sided functioning is expected of a wetland, based on the habitat condition - either aquatic or terrestrial. In a wetland that has served only as an aquatic habitat, filtration, and water resource could be degraded due to aquaculture, drainage, and run-off from fertilized crops and pesticides (Brinson and Malvárez, 2002). In contrast, a wetland that has only served as a terrestrial area that restricts human activities owing to its wet soil and water could be directly transformed via reclamation for use as agricultural land and as a residential area (Dahl, 2000; Hefner and Brown, 1984). Consequently, numerous wetlands are degraded and are being converted for human overuse and misuse more rapidly than any other ecosystem. Additionally, wetlands are the most threatened habitats among the various ecosystems (Dudgeon et al., 2006).

A common understanding of the causes of wetland loss and alteration is dominated by simplifications that, in turn, are the basis for many environment-development policies (Finlayson and Eliot, 2001). Institutional factors mediate responses of people to 
economic opportunities and it further affects condition of wetlands (Gardner, 2011; Lambin et al., 2001). Industrial, residential, and areas for maintenance of the society have substituted agricultural land and wetlands (Giblett, 1996). Urbanization, as a major cause of wetland loss, is also included in this process. Wetland loss and its causes have reflected the phases of time (Finlayson, 2012; Salafsky et al., 2002).

In the present study, we examined the historical distribution of wetlands, the process, and causes of wetland loss in South Korea during the past century. South Korea started developing rapidly since the 1960s (Levy and Kuo, 1991). The rapid industrialization over the past 40 years also resulted in a steep increase in its demand for natural resources (Lim and Tang, 2002). As a result, South Korea today has one of the largest relative ecological deficits of any country. In particular, many natural habitats and their biodiversity, including wetlands in South Korea, have been lost and degraded as a result of human activities even before realizing their ecological and economic functions. We focused on a regional scale where floodplain wetlands are widely developed along the river channel. This approach provides more detail on the wetland and on the process and causes of wetland loss at different times.

Our study had three main objectives: (1) to identify the historical distribution of wetlands, (2) to track the wetland area and its conversion to alternative land-use types, and (3) to examine the driving factors (causes) behind wetland loss. We attempted to summarize the trends and processes of wetland loss using historical maps and aerial photography.

\section{Material and methods}

\section{Study area}

We traced the distribution of wetlands from 1918 to 2011 in the lower part of the Nakdong River in South Korea (Figure 1). Historically, numerous wetlands have been distributed in this area (Do et al., 2012a) because there are large rivers (Nakdong River) and their tributaries (Nam River) flowing through a flat valley with fluvial soil (Son and Jeon, 2003). Approximately 20\% of all the wetlands in South Korea are concentrated within this area (Do et al., 2012b). Although the area is dominated by forest (52.18\%), agricultural and urbanized areas account for $31.97 \%$ and $5.07 \%$, respectively.

\section{Identifying wetland distribution}

Changes in the historical distribution of wetlands over the past 100 years were determined using 1:25,000 topographic maps. The oldest topographical map drawn to scale for this area was published in 1918 by the General of the Chosun Dynasty belonging to the Japanese Government. However, at that time the map had been produced only at a 1:50,000 scale. Seven topographical maps since $1963(1963,1978$, 1986, 1995, 1998, 2004, and 2009) and an aerial map (2011) published by the National Geographic Information Institute of Korea were used to identify wetland distribution. All topographical maps were digitized after scanning at 600 dpi. Digitized maps were geometrically corrected based on a digital 1:25,000 topographic map produced in 2011. Geometric corrections were made possible based on Ground Control Point (GCP), which are fixed points and artificial landmarks that undergo little change over time (e.g., roads and bridges). The maps were corrected using the polynomial method in ERDAS IMAGINE 9.1 (Intergraph Corporation, USA). A minimum of 12 GCPs were selected for the transformation. Image transformation minimized the errors in root mean square 
values to less than $2.1 \mathrm{~m}$. Wetlands were identified using the legend (wetland, surface of water, rivers are not included) of the map, and each wetland was delineated using the vector editor tool in ArcMAP 9.3 (ESRI, USA).

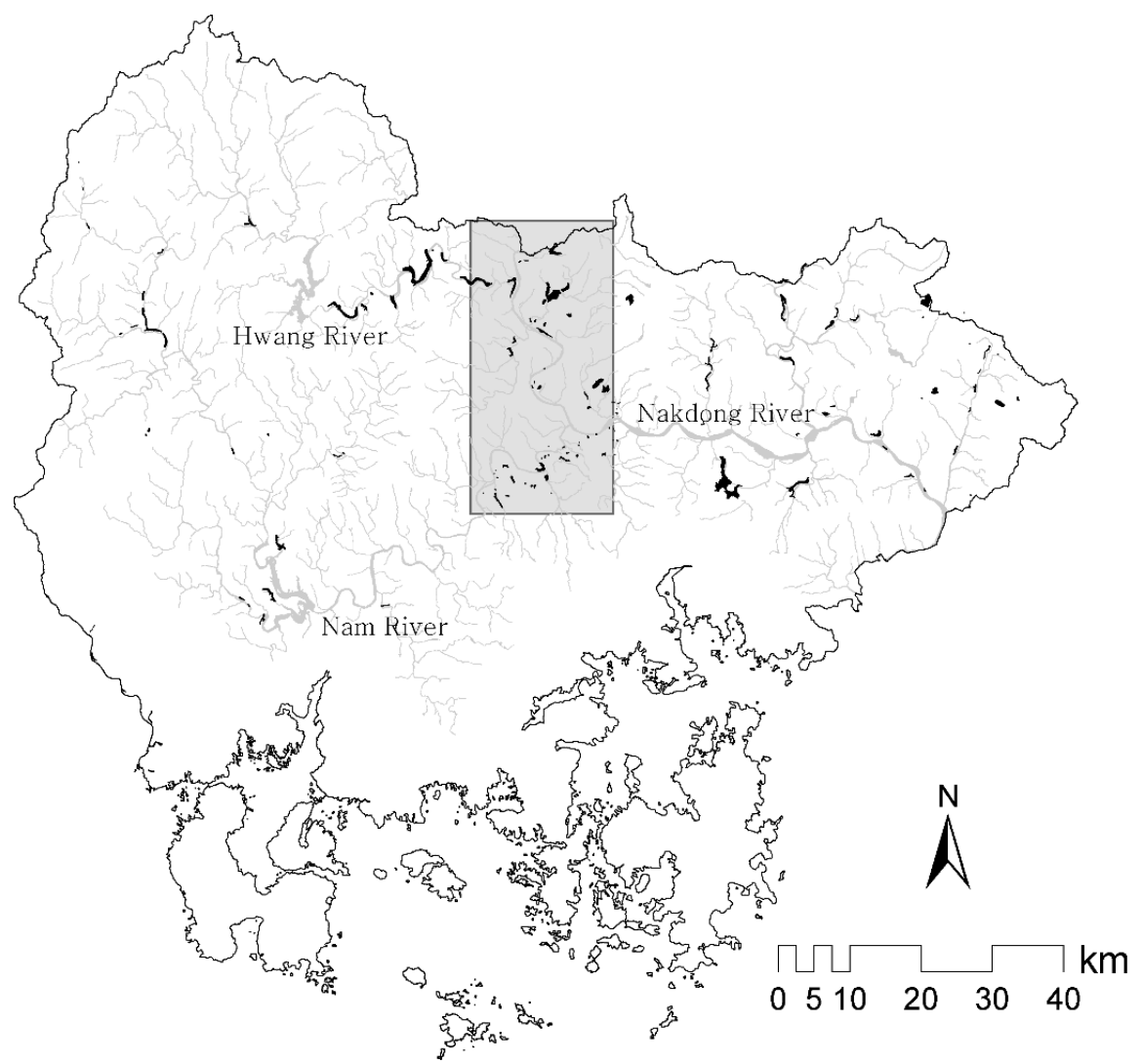

Figure 1. Wetland distribution in the study area (study area $=$ grey color square with black line, black color $=$ wetland, grey color $=$ river $)$

\section{Change of wetland distribution and loss of wetland}

The causes of wetland loss or conversion were classified into six categories (agriculture land, levee, road, bare land, industrial area, and residential area). The areas of wetland loss or conversion were identified by comparing with the land condition of the following year. In addition, we confirmed the changes by visiting all wetlands in the study area from May 2011 to July 2012. Wetland boundaries obtained from the map were corrected with data collected during this field survey. The number of wetlands, the area that they cover, and the mean nearest-neighbor distance (MNN) between wetlands were calculated each year for identifying the process of wetland loss and changes in the distribution pattern of wetlands at a large scale. MNN is the minimum distance between wetlands, based on the shortest distance between their edges. Additionally, the landscape diversity indices, including Shannon's diversity index (SDI) and Shannon's evenness index (SEI), were calculated based on the number and area of wetlands each year. SDI is a measure of relative patch diversity and is equal to zero when there is only one patch in the landscape, and it increases as the number of patch types or the proportional distribution of patch types increases. SEI is a measure of patch distribution and abundance. It is equal to zero when the observed patch distribution is low, and it 
approaches one when the distribution of patch types becomes more even. The mean perimeter-area ratio (MPAR) and the mean patch fractal dimension (MPFD) for each year were chosen to assess the alternation of wetland shape at the habitat level. MPAR is a simple ratio of patch perimeter to area, in which patch shape is confounded with patch size; holding the shape constant, an increase in patch size will cause a decrease in the perimeter-area ratio. MPFD is a measure of the ratio of perimeter per unit area, and it increases as the wetlands become more irregular. All spatial and temporal analyses and data processing were performed using FRAGSTATS Version 3.3 for GIS analysis (McGarigal et al., 2002).

Linear regression analysis was used to examine the relationships between the number of wetlands, area, mean distances between wetlands, wetland shape across the years using PASW Statistics 18. The $\mathrm{r}^{2}$ and standardized beta (B) of linear regression were used to identify the positive and negative relationship between variables and years.

\section{Result}

\section{Wetland loss}

In the past century, the number of wetlands and the total wetland area within the study area declined by approximately $65 \%$ and $70 \%$, respectively. However, the reduction ratio of the number of wetlands in comparison with the previous year, declined steadily with each year. In particular, the number of wetlands and wetland areas adjacent to contributories (Nam River) decreased more when compared with wetlands adjacent to a main river (Nakdong River, Figure 2). The reduction of wetland areas $\left(B=-0.99, r^{2}=0.98, p<0.001\right)$ was steeper than the reduction in the number of wetlands $\left(\mathrm{B}=-0.924, \mathrm{r}^{2}=0.85, \mathrm{p}<0.001\right)$.

At the landscape level, MNN among wetlands was significantly more each year, indicating the increased isolation of the wetlands (Table 1). The Shannon diversity index (SDI) and the Shannon evenness index (SEI) decreased significantly, as the years passed. In particular, the reduction ratio of SDI was higher than that of SEI. This also means that the reduction in the number of wetlands was more effected by a decrease of SDI. At the habitat level, MPAR and MPFD increased significantly indicating that the area of each wetland decreased continuously, and the physical dimensions of each wetland became more complex.

Table 1. Change of landscape indices and their trends in the study area

\begin{tabular}{c|c|c|c|c|c}
\hline Year & SDI & SEI & MNN & MPAR & MPFD \\
\hline 1918 & 3.83 & 0.78 & 685.97 & 244.62 & 1.30 \\
1963 & 3.40 & 0.70 & 652.23 & 436.83 & 1.33 \\
1978 & 3.27 & 0.75 & 873.12 & 328.44 & 1.32 \\
1986 & 3.26 & 0.74 & 785.81 & 351.29 & 1.32 \\
1998 & 2.43 & 0.60 & $1,081.31$ & 382.80 & 1.33 \\
2004 & 2.76 & 0.68 & 965.01 & 364.16 & 1.32 \\
2009 & 2.65 & 0.63 & 913.34 & 534.81 & 1.35 \\
2011 & 2.51 & 0.65 & $1,050.28$ & 568.05 & 1.35 \\
\hline $\mathrm{B}$ & -0.913 & -0.775 & 0.792 & 0.716 & 0.828 \\
$\mathrm{r}^{2}$ & 0.834 & 0.601 & 0.627 & 0.512 & 0.685 \\
$\mathrm{p}$ & 0.002 & 0.024 & 0.019 & 0.046 & 0.011 \\
\hline
\end{tabular}

* SDI = Shannon diversity index, SEI = Shannon evenness index, MNN = mean nearestneighbor distance, MPAR = mean perimeter-area ratio, MPFD = mean patch fractal dimension 

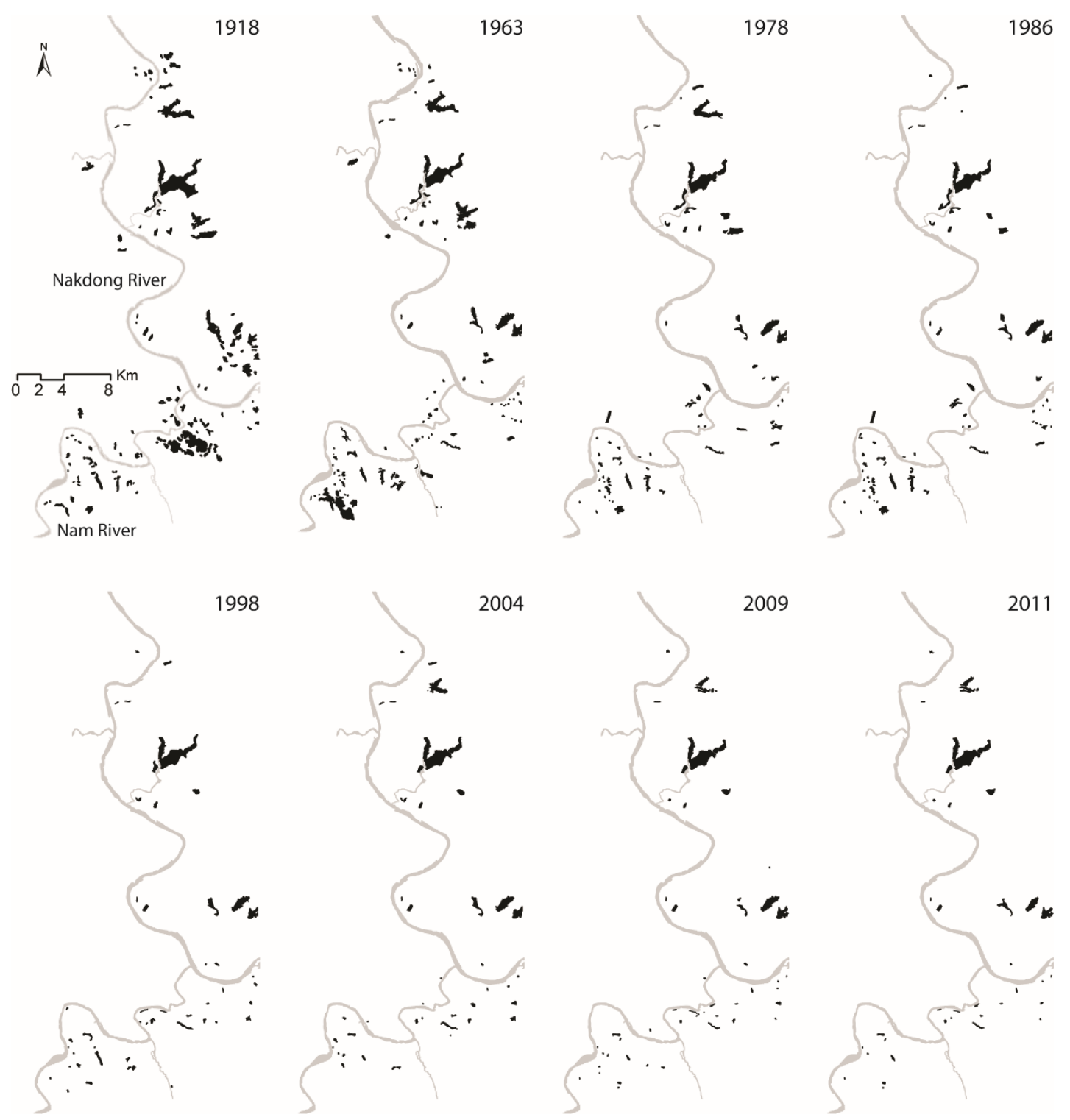

Figure 2. Change of wetland distribution in the study site (wetlands $=$ black, river channel $=$ grey)

\section{Causes of wetland loss}

The major cause of wetland loss was associated with agricultural development in the region. Approximately $42 \%$ of lost wetlands were diminished due to conversion from wetlands to agricultural lands. On the floodplain, which is a major type of wetland in this area, levees were constructed for flood control. Approximately $39 \%$ of the wetland area was lost or altered by the construction of levees. Development of roads, factories, and residential areas associated with industrialization and urbanization accounted for approximately $12 \%$ of the total loss of wetland area. The bare land that was converted from wetlands accounted for a further $7 \%$ of the total area of wetland that was lost. These areas were converted to specific land-use types, especially levees and agricultural lands. In the early period (1960-70), agricultural development was the dominant cause of wetland loss. In contrast, loss caused by industrialization and urbanization has been 
recorded since the 1990s, although agricultural lands and levees have always been major causative factors (Figure 3).

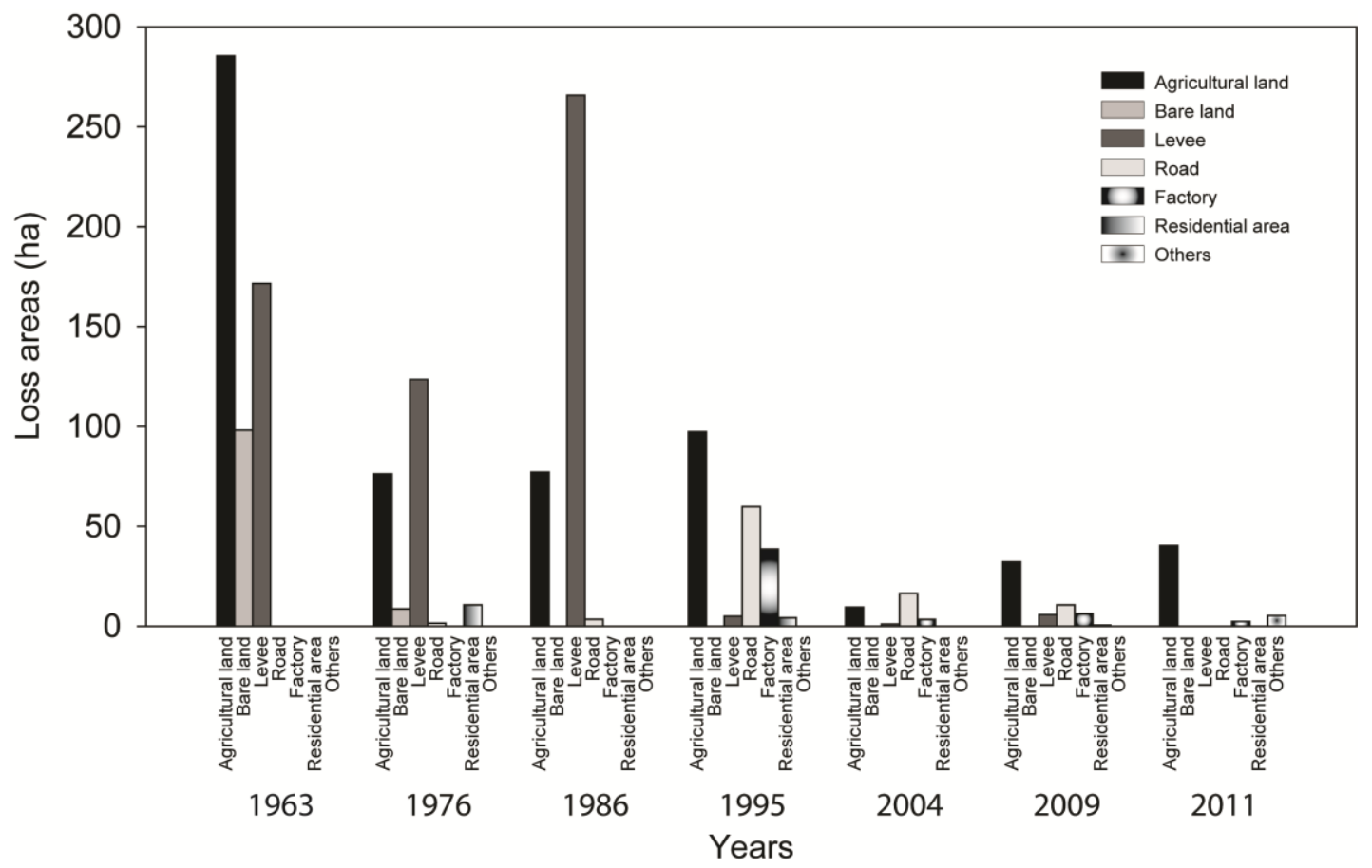

Figure 3. Changes in the contribution of various factors to wetland loss over the years

\section{Discussion}

\section{Process of wetland loss}

Numerous wetlands have been lost as a result of human activities associated with economic development, such as agricultural development, industrialization, and urbanization. The process of wetland loss and alternation appeared to be divided into five stages (Figure 4). (1) Wetlands were directly lost by reclamation for development of agricultural land. (2) Levees were constructed on wetlands for prevention of flood damage to agricultural land. (3) Houses for farmers were built on the wetlands after reclamation. (4) Roads constructed as infrastructure for the farms fragmented the wetlands into small parts. (5) Factories were built on reclaimed paddy fields and wetlands.

The wetlands were a major focus for agricultural development (Liu et al., 2004). In Asian countries where rice is cultivated along with aquaculture, the wet soil, alluvial soil, and flat land of wetlands are attractive to farmers (Zhang et al., 2010). The construction of levees will have a serious impact on wetland distribution. Many wetlands were directly destroyed owing to the construction of levees, and these levees may further isolate the remaining wetlands by reducing natural flooding, which is a critical variable to maintain the wetland aquatic condition and biota (Casanova and Brock, 2000; Middleton, 1999). Recently, local governments have been facilitating reclamation and relocation of industrial complexes to agricultural areas (including rice fields) to increase industrial development in the rural areas.

Although partial wetlands remain after land reclamation, they undergo further physical modification. The size becomes smaller, the shape more complex, and the 
wetlands become isolated. Most of the remaining wetlands were largely used for irrigation. Do et al. (Do et al., 2012b) argued that only the wetlands that had specific usages remained.

During field survey, we also confirmed that most remaining wetlands were used for irrigation, and they were designated as a reservoir by the land use policy of the local government. They were also designated as a protected area by acts associated with wetlands and wildlife. However, the size and shape of these wetlands can be modified by any degree of change in usage. The construction of roads was a major cause of wetland fragmentation. Although the impact of fragmentation may be less severe than wetland loss, fragmentation is also critical to migrating species and regional biodiversity (Rosenzweig, 1995). In comparison with small habitats, large habitats are more likely to intercept potential colonists, and to have lower extinction rates owing to their larger population size (McArthur and Wilson, 1967; O'Connell et al., 2013). A more modified habitat contains more periphery-adjacent area. Species that depend on resources found in the interior habitat may avoid the habitat at the edges because of its less favorable quality, predation risk, and microhabitat conditions (Fletcher et al., 2007; Sebastián-González and Green, 2014).

The loss by conversion from wetland to agricultural land, especially paddy fields, might have different ecological pathways from those for agricultural land with dry farming practices (i.e., corn field, wheat field, etc.). The paddy field is a temporary wetland that harbors many of the species that breed in natural temporary ponds (Lawler, 2001). Additionally, the paddy field has the potential to help sustain the regional diversity of many invertebrates and vertebrates that depend on aquatic/semi-aquatic habitat (Bambaradeniya and Amarasinghe, 2004). However, to maintain the ecological function as a wetland, low impact farming practices are required. The intensive farming practices with insecticide and fertilization have a critical effect on the biodiversity in paddy fields (Hegde et al., 2014; Simpson et al., 1994). Further, intensive farming requires more agricultural infrastructures (e.g., levee and pipe channel) that leads to degradation of hydrological conditions of wetlands. Recently, winter flooding has been suggested as an important management practice to improve biodiversity in the paddy field. Winter flooding maintains the wet condition similar to a permanent wetland and supports aquatic biota (Fujioka et al., 2010; Kim et al., 2011).

On the other hand, areas of abandoned paddy fields have increased with the changes in the structure of rural economy and a decrease in the rural population (Taylor and Martin, 2001). The abandoned paddy fields are good potential areas for wetland restoration. In particular, paddy fields converted from wetlands are one of the best sites for restoring historical wetlands (Nakamura et al., 2006). Such abandoned paddy fields generally maintain a soil seed bank of wetland species (Middleton, 1999; Middleton, 2003). Further, such fields require fewer modifications as they maintain similar hydrologic conditions with the floodplains in the region. More retrospective research on land use change in the floodplain area will provide essential understanding for implementing an effective wetland restoration and management plan. 

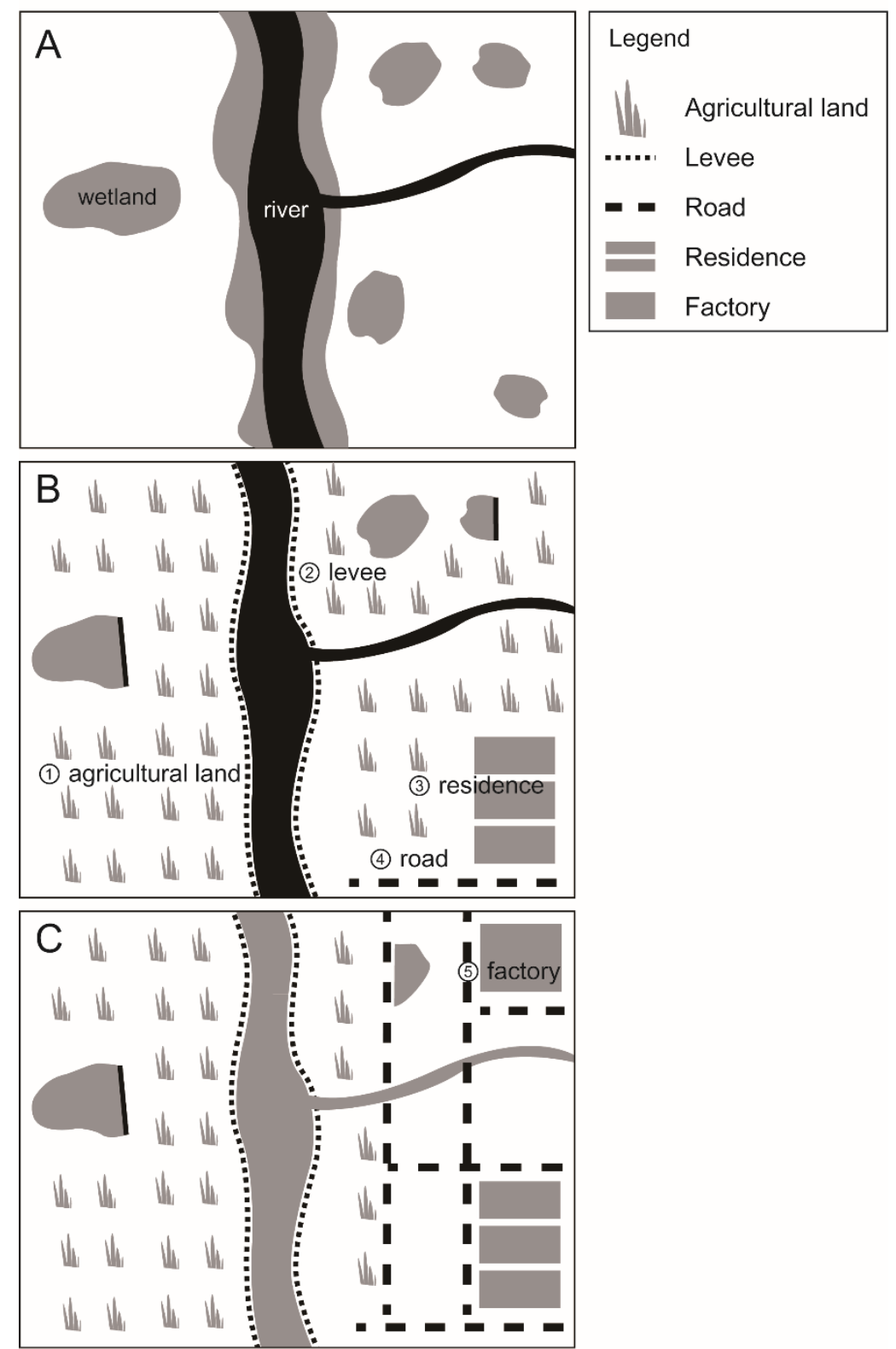

Figure 4. Schematic representation of the process of wetland loss; the numbers in circles represent the process stages; A: natural floodplain, B: initial reclamation for agricultural field (early-middle stage), $C$ : construction of urban infrastructure (late stage)

\section{REFERENCES}

[1] Assessment, M.E. (2005): Ecosystems and human well-being: Wetland and water Synthesis. Available online: http://www.millenniumassessment.org/proxy/Document 358.

[2] Bambaradeniya, C.N., Amarasinghe, F.P. (2004): Biodiversity associated with the rice field agroecosystem in Asian countries: a brief review.-International Water Management Institute, Colombo

[3] Brinson, M.M., Malvárez, A.I. (2002): Temperate freshwater wetlands: types, status, and threats.-Environmental Conservation 29:115-133.

[4] Casanova, M.T., Brock, M.A. (2000): How do depth, duration and frequency of flooding influence the establishment of wetland plant communities?-Plant Ecology 147:237-250. 
[5] Dahl, T.E. (2000): Status and trends of wetlands in the conterminous United States 1986 to 1997.-US Fish and Wildlife Service, Washington

[6] Do, Y., Kim, H.A., Kim, S.B., Im, R.Y., Kim, S.K., Joo, G.J. (2012a): Awareness and exploitation of wetland during the Joseon Dynasty.-Korean Wetland Society Journal 14:329-340.

[7] Do, Y., Kim, J.Y., Im, R.Y., Kim, S.B., Choi, J.Y., Joo, G.J. (2012b): Spatial Distribution and Social Characteristics for Wetlands in Gyeongsangnam-do Province.-Korean Journal of Limnology 45:252-260.

[8] Dudgeon, D., Arthington, A.H., Gessner, M.O., Kawabata, Z.I., Knowler, D.J., Lévêque, C., Naiman, R.J., Prieur-Richard A.H., Soto, D.,Stiassny, M.L.J.,SullivanC.A. (2006): Freshwater biodiversity: importance, threats, status and conservation challenges.Biological Reviews 81:163-182.

[9] Finlayson, C., Eliot, I. (2001): Ecological Assessment and Monitoring of Coastal Wetlands in Australia's Wet-Dry Tropics: A Paradigm for Elsewhere?-Coastal Management 29:105-115.

[10] Finlayson, M.C. (2012): Forty years of wetland conservation and wise use-Aquatic Conservation: Marine and Freshwater Ecosystems 22:139-143.

[11] Fletcher, J., Robert, J., Ries, L., Battin, J., Chalfoun, A.D. (2007): The role of habitat area and edge in fragmented landscapes: definitively distinct or inevitably intertwined?Canadian journal of zoology 85:1017-1030.

[12] Fujioka, M., Lee,S.D., Kurechi, M., Yoshida, H. (2010): Bird use of rice fields in Korea and Japan.-Waterbirds 33:8-29.

[13] Gardner, R.C. (2011): Lawyers, swamps, and money: US wetland law, policy, and politics.-Island Press, Washington.

[14] Giblett, R.J. (1996): Postmodern wetlands: culture, history, ecology.-Edinburgh University Press, Edinburgh

[15] Hefner, J.M., Brown, J.D. (1984): Wetland trends in the southeastern United States.Wetlands 4:1-11.

[16] Hegde, G., Mandya, M., Gokarnakar, S.S., Babu, V.N., Shivaramaiah, V.N., Krishnamurthy, S.V. (2014): Influence of Combinations of Pesticides and Fertilizers on Aquatic Productivity.-Journal of Environmental Protection 5(5): 434-440.

[17] Keddy, P.A. (2010): Wetland ecology: principles and conservation.-Cambridge University Press, Cambridge

[18] Kim, J.O., Lee, S.H., Jang, K.S. (2011): Efforts to improve biodiversity in paddy field ecosystem of South Korea.-Reintroduction 1:25-30.

[19] Lambin, E.F.,Turner, B.L., Geista, H.J., Agbola, S.B., Angelsen, A., Bruce, J.W., Coomes, O.T., Dirzo, R., Fischer, G., Folke, C., George, P.S., Homewood, K., Imbernon, J., Leemans, R., Li, X., Moran, E.F., Mortimore, M., Ramakrishnan, P.S., Richards, J.F., Skåness, H., Steffen, Stone, G.D., Svedin, U., Veldkamp, T.A., Vogel, C., Xu, J. (2001): The causes of land-use and land-cover change: moving beyond the myths.-Global Environmental Change 11:261-269.

[20] Lawler, S.P. (2001): Rice fields as temporary wetlands: a review.-Israel Journal of Zoology 47:513-528.

[21] Levy, B., Kuo, W.J. (1991): The strategic orientations of firms and the performance of Korea and Taiwan in frontier industries: lessons from comparative case studies of keyboard and personal computer assembly.-World Development 19(4):363-374.

[22] Lim, J.H., Tang, S.Y. (2002): Democratization and Environmental Policy-Making in Korea.-Governance 15:561-582.

[23] Liu, H., Zhang, S., Li, Z., Lu, X., Yang, Q. (2004): Impacts on wetlands of large-scale land-use changes by agricultural development: the small Sanjiang Plain, China.-AMBIO: A Journal of the Human Environment 33:306-310. 
[24] McArthur, R.H., Wilson, E.O. (1967): The theory of island biogeography.-Princeton University Press, New Jersey

[25] McGarigal, K., Cushman, S.A., Neel, M.C., Ene, E. (2002): FRAGSTATS: Spatial pattern analysis program for categorical maps. Computer software program produced by the authors at the University of Massachusetts, Amherst.

[26] Middleton, B. (1999): Wetland restoration, flood pulsing, and disturbance dynamics.John Wiley \& Sons, New York

[27] Middleton, B. (2003): Soil seed banks and the potential restoration of forested wetlands after farming.-Journal of Applied Ecology 40:1025-1034

[28] Nakamura, K., Tockner, K., Amano, K. (2006): River and wetland restoration: lessons from Japan.-BioScience 56:419-429.

[29] O'Connell, J.L., Johnson, L.A., Beas, B.J., Smith, L.M., McMurry, S.T., Haukos, D.A. (2013): Predicting dispersal-limitation in plants: optimizing planting decisions for isolated wetland restoration in agricultural landscapes.-Biological Conservation 159:343354.

[30] Rosenzweig, M.L. (1995): Species diversity in space and time.-Cambridge University Press, Cambridge

[31] Salafsky, N., Margoluis, R., Redford, K.H., Robinson, J.G. (2002): Improving the practice of conservation: a conceptual framework and research agenda for conservation science.-Conservation Biology 16:1469-1479.

[32] Sebastián-González, E., Green, A.J. (2014): Habitat Use by Waterbirds in Relation to Pond Size, Water Depth, and Isolation: Lessons from a Restoration in Southern Spain.Restoration Ecology 22:311-318.

[33] Simpson, I.C., Roger, P.A., Oficial, R., Grant, I.F. (1994): Effects of nitrogen fertilizer and pesticide management on floodwater ecology in a wetland ricefield.-Biology and Fertility of Soils 17:138-146.

[34] Son, M.W., Jeon, Y.G. (2003): Physical geographical characteristics of natural wetlands on the downstream reach of Nakdong River.-Journal of the Korean Association of Regional Geogrphers 9:66-76.

[35] Taylor, J.E., Martin, P.L. (2001): Human capital: Migration and rural population change.- In: Gardner, B.L. \& RausserG.C. (ed.) Handbook of Agricultural Economics, Elsevier, Netherland

[36] Zhang, J., Ma, K., Fu, B. (2010): Wetland loss under the impact of agricultural development in the Sanjiang Plain, NE China.-Environmental Monitoring and Assessment 166:139-148. 